\title{
As Mulheres na Gestão do Esporte Brasileiro: um estudo pioneiro
}

\author{
Carolina de Campos Derós * \\ Silvana Vilodre Goellner **
}

GOMES, Euza Maria de Paiva. A participação das mulheres na gestão do esporte brasileiro: desafios e perspectivas. Rio de Janeiro: Quartet: FAPERJ, 2008.

\begin{abstract}
Resumo: Trata-se da resenha do livro Participação das Mulheres na Gestão do Esporte Brasileiro: desafios e perspectivas, escrito por Euza Gomes e publicado pela editora Quartet e Faperj (2008). Tem como objetivo analisar a pesquisa realizada, bem como suas contribuições para o campo dos estudos sobre mulheres e esporte no Brasil.
\end{abstract}

Palavras-chave: Mulheres. Esportes. Organização e administração. Identidade de Gênero.

O final século XX foi bastante fecundo para as mulheres ao pensarmos na ocupação do espaço público, fundamentalmente no período pós-guerra. Se, por um lado, essa percepção é animadora, por outro, não significa afirmar que as desigualdades entre os gêneros tenha sido suprimida em função dessa ocupação. A pesquisa realizada pelo Núcleo de Opinião Pública da Fundação Perseu Abramo, em 2001, é exemplar dessa afirmação. Com o objetivo de investigar a participação da mulher brasileira nos espaços públicos e privados, foram realizadas 2.502 entrevistas, cujas questões envolveram temáticas como suas percepções sobre as mudanças na condição da mulher, expectativas pessoais e políticas, trabalho remunerado e trabalho doméstico, práticas de lazer, sexualidade, violência, entre outras. As análises desenvolvidas pela equipe que conduziu a investigação

* Mestranda em Ciências do Movimento Humano - Escola de Educação Física da UFRGS. Porto Alegre, RS, Brasil. E-mail: carolderos@gmail.com

** Doutora em Educação. Professora Adjunta da Escola de Educação Física da UFRGS. Porto Alegre, RS, Brasil. E-mail: goellner@terra.com.br 
são reveladoras da situação das brasileiras no âmbito do espaço público. A inserção no mercado de trabalho é apontada como o principal caminho que levou as mulheres às experiências públicas, o que, de certo modo, colaborou para a construção de sua autonomia, ao menos por possibilitar mais independência econômica em relação aos maridos, companheiros e pais. No entanto, essa inserção trouxe consigo certo ônus, inclusive, o da dupla jornada de trabalho visto que a ampliação da mulher no trabalho fora de casa não correspondeu à divisão das tarefas domésticas. Ao serem indagadas sobre a primeira atitude que tomariam para que a vida das brasileiras tivesse melhorias, despontaram como principais respostas espontâneas: o fim das discriminações no mercado de trabalho (47\%), a igualdade dos direitos (10\%), o combate à violência contra as mulheres $(9 \%)$, maior liberdade $(6 \%)$, menos machismo e mais reconhecimento por parte dos homens (4\%) (VENTURI; RECAMÁN; OLIVEIRA, 2004).

Esses dados mostram-se instigantes para analisarmos a participação das brasileiras na gestão esportiva, tema do livro Participação das Mulheres na Gestão do Esporte Brasileiro: desafios e perspectivas, escrito por Euza Maria de Paiva Gomes, que resulta da sua tese de doutoramento defendida junto ao Programa de Pós-Graduação em Educação Física, da Universidade Gama Filho, sob orientação de Ludmila Mourão.

Para a autora, apesar da reconhecida ampliação que as mulheres brasileiras tiveram no que tange a sua inserção no mercado de trabalho, a realidade da sua presença na gestão esportiva brasileira é outra: além de pequena, essa se deu pelas vias da conciliação, sem grandes lutas nem embates, já que o processo de visibilidade da mulher no esporte não foi marcado pela intenção de mudar a condição das mulheres nessa área mas, talvez, de adequar-se ao já instituído. Segundo Euza, não houve, no esporte brasileiro, um movimento feminino - muito menos feminista - em prol da equalização de gênero. Apesar dessa ausência, identifica alguns avanços nesse campo embora a presença masculina ainda seja predominante nas diferentes organizações gestoras do esporte brasileiro - federações, confederações e secretarias e nas diferentes funções - dirigentes, técnicos e árbitros.

Movimento, Porto Alegre, v. 15, n. 02, p. 235-242, abril/junho de 2009. 
Essa presença reflete a própria participação das mulheres no campo esportivo. Se pensarmos no esporte de alto rendimento, por exemplo, somente em 1932 tivemos uma única atleta participando dos Jogos Olímpicos, a nadadora Maria Lenk, número esse significativamente ampliado na última edição dos Jogos realizados em Pequim, em 2008. A delegação brasileira foi composta por 277 atletas, sendo 144 homens e 133 mulheres.

Seguindo essa trilha, Euza Gomes desenvolve uma pesquisa através da qual busca compreender como as mulheres são representadas nas esferas do poder da gestão do esporte de alto rendimento no Brasil, em suas diferentes instituições: Federativas, Confederativas, na Secretaria Nacional de Alto Rendimento (SNEAR) do Ministério dos Esportes e no Comitê Olímpico Brasileiro. Justifica sua escolha não apenas pela ausência de pesquisas dessa natureza mas, ainda, porque apesar das grandes mudanças culturais ocorridas no século XX, a entrada das mulheres no campo da gestão esportiva não se deu com a mesma velocidade, visto que este espaço de atuação é constituído como de reserva masculina.

O pioneirismo do estudo de Euza é uma das suas qualidades e, indubitavelmente, fornece muitas contribuições para o avanço das pesquisas sobre o esporte nacional, inclusive por apresentar dados inéditos sobre as questões de gênero na gestão esportiva. Dados esses que, se for de interesse político, podem contribuir para a elaboração de políticas direcionadas para o acréscimo da participação das mulheres neste campo de atuação profissional.

Na primeira parte do livro, Euza dialoga com diferentes autores/as cujas pesquisas apontam dados referentes à inserção e ao perfil das mulheres brasileiras nos espaços público e privado, bem como análises acerca das relações de poder presentes em diferentes instâncias sociais. Neste item, buscou elementos para entender as transformações nas representações que marcam os deslocamentos das mulheres do espaço doméstico - em um período no qual o cuidado com a casa e com os filhos aparecem como as únicas atribuições que as valorizavam como "rainhas do lar" - para o espaço público ou para a entrada no "mundo dos homens".

Movimento, Porto Alegre, v. 15, n. 02, p. 235-242, abril/junho de 2009. 
A partir dessa discussão, elabora um painel sobre a visibilidade feminina nas diferentes esferas da vida pública, mostrando que, embora as mulheres constituam metade da população, suas representantes equivalem a $5 \%$ dos líderes mundiais. Mesmo com esse baixo percentual, afirma que nunca houve tantas mulheres no comando, especialmente nos congressos e parlamentos de diferentes países, onde ocupam 16,3\% das cadeiras. Segundo a autora, no contexto nacional, essa presença, mesmo que timidamente, vem se ampliando nos primeiros escalões do governo (ministérios e secretarias estaduais), Congresso Nacional, Senado, Assembleias Legislativas Estaduais e Câmaras Municipais. Ainda assim, o número de mulheres em cargos de comando não atinge o previsto com as cotas, que pretendem garantir a presença de $30 \%$ de mulheres nas listas partidárias para cargos legislativos

Sobre esse tema, Euza menciona vários estudos de natureza qualitativa, cujos resultados apontam que a maior representatividade das mulheres situa-se em áreas como da educação e da promoção social, observada, não raras vezes, como um prolongamento daquilo que seria a "condição feminina" no que tange às atividades domésticas. Essa mesma tendência é identificada na gestão das principais instituições esportivas brasileiras, nas quais as mulheres ocupam cargos decisórios no âmbito da educação e do lazer e apresentam uma participação restrita no campo da gestão do esporte de alto rendimento.

Nesse tópico, faz uma análise baseada em autores/as internacionais, sobre experiências de liderança e gestão de mulheres no esporte. A partir desses estudos, afirma que é possível perceber uma maior participação feminina no esporte naqueles países que, de alguma forma, adotaram políticas de ação afirmativa direcionadas para esse fim. Situação essa que não acontece no Brasil, nem mesmo a partir da recomendação que o Comitê Olímpico Internacional fez a todas as instituições que atuavam sob as suas normativas, indicando que a composição de seus órgãos executivos deveriam ter, pelo menos, $10 \%$ de mulheres até o ano 2000 , e $20 \%$, até o ano 2005 . O quadro apresentado por Euza, datado de 2006, evidencia os seguintes percentuais da participação das mulheres em cargos diretivos: Comitê Olímpico Brasileiro (4\%), Confederações Vinculadas/Filiadas

Movimento, Porto Alegre, v. 15, n. 02, p. 235-242, abril/junho de 2009. 
$(1,8 \%)$, Federações Esportivas Nacionais $(6,5 \%)$ e Comitê Paraolímpico Brasileiro (30\%).

A autora afirma que, mesmo pequena, essa participação se ampliou nos últimos 10 anos. No entanto, apesar dessa conquista, continua sendo sua a atribuição de cuidar da casa e dos filhos dificultando, sobremaneira, uma maior ascensão profissional. Razão pela qual, em muitos dos estudos em que se apoia para desenvolver sua pesquisa, evidencia-se que é grande o número de mulheres solteiras nos cargos de comando e que, muitas delas, ao casarem-se, acabam por abandonar suas funções na gestão esportiva, por serem ainda responsáveis pelo trabalho doméstico.

Feita essa introdução ao tema, Euza recorre à história do esporte nacional para evidenciar a atuação de algumas mulheres pioneiras que participam/participaram do desenvolvimento da gestão esportiva brasileira. Descreve, então, a atuação de Maria Emma Hulda Lenk Ziegler (1915-2007), como uma importante protagonista da história das mulheres no esporte, cuja trajetória tornou-se uma "porta de entrada" para que pudessem ascender ao esporte de alto nível, inclusive no campo da gestão esportiva, visto que foi membro do Conselho Nacional de Esportes (anos 40) e a primeira diretora de uma escola superior de Educação Física: a Escola de Educação Física e Esportes da Universidade do Brasil, em 1968.

Na sequência, são apresentadas pequenas histórias de algumas mulheres que comandaram equipes de Seleção Brasileira em campeonatos internacionais e nos Jogos Olímpicos. Um grupo que, em conjunto com as presidentes de federações e confederações, árbitras e bandeirinhas, ainda é numericamente insignificante. Nesse momento, Euza faz ver que, no Brasil, a grande maioria das mulheres que atuam como técnicas esportivas comandam equipes de categorias de base e seu trabalho é muito mais voltado para a formação e para atividades recreativas e de lazer do que para o esporte de alto rendimento.

Fundamentada no estudo realizado por Gabriela Souza de Oliveira, intitulado "Representações sociais de mulheres técnicas sobre o comando de equipes esportivas de alto nível" (2002), no qual são entrevistadas 12 técnicas, Euza indica que quase todas tiveram de

Movimento, Porto Alegre, v. 15, n. 02, p. 235-242, abril/junho de 2009. 
optar entre a dedicação exclusiva à família e a dedicação exclusiva à carreira. Menciona o depoimento de Maria Helena Cardoso - extécnica da Seleção Feminina de Basquete - quando afirma que algumas mulheres modificam seus comportamentos para atender a algumas especificidades necessárias ao treinamento das equipes, aproximando-os de características tidas como masculinas. Apesar disso, não deixam de utilizar algumas representações associadas ao feminino como questões afeitas à maternidade, as quais recorrem, algumas vezes, para estabelecer uma maior aproximação com os/as atletas.

A partir dessa "revisão de literatura" como denomina esse item, descreve os procedimentos metodológicos adotados para a realização da pesquisa que é caracterizada como de cunho qualitativo. A coleta de dados iniciou com um mapeamento das diferentes instâncias da gestão esportiva brasileira, objetivando identificar a presença de mulheres. Posteriormente, foram eleitas 14 gestoras para atuarem como colaboradoras da pesquisa, distribuídas em dois grupos: gestoras que foram nomeadas e gestoras que foram eleitas para os cargos diretivos. A amostra configurou-se, portanto, com três mulheres que atuavam na Secretaria Nacional do Esporte de Alto Rendimento do Ministério dos Esportes, uma do Comitê Olímpico Brasileiro, duas de Confederações e oito de Federações.

Após descrever o perfil de cada uma delas, ressaltando sua trajetória pessoal e profissional até a chegada ao posto no qual atuavam, a autora desenvolve suas reflexões com o intuito de compreender as motivações, os desafios e as dificuldades encontradas na construção de suas carreiras. Analisou, ainda, as relações de gênero existentes na gestão esportiva, bem como as mudanças que essas mulheres promoveram (ou tentaram promover) nas entidades esportivas que estavam sob sua direção.

Através das suas falas, Euza pôde traçar um perfil das atuais gestoras brasileiras, que a permitiu concluir que essas mulheres possuem uma média de 40 anos de idade, são, em sua grande maioria, solteiras e se dedicam a um trabalho voluntário em nome do seu amor ao esporte. A maior dificuldade apontada por todas encontra-se na falta de verbas para administrarem suas entidades esportivas, e a necessidade de, por serem mulheres, provarem diariamente a sua competência,

Movimento, Porto Alegre, v. 15, n. 02, p. 235-242, abril/junho de 2009. 
já que seu trabalho é visto com certa desconfiança, fundamentalmente entre os gestores.

Várias das entrevistadas mencionam que a imagem da mulher centrada no gerenciamento do lar e nos cuidados com a família ainda é predominante na sociedade brasileira. Por essa razão, percebe-se que, ao participarem da gestão esportiva, avançaram em suas carreiras e, de certo modo, romperam algumas barreiras. $\mathrm{O}$ fato de serem solteiras e não terem filhos aparece como um elemento facilitador dessa ascensão.

As mulheres casadas - minoria no estudo - trabalham lado-a-lado com os seus parceiros, inclusive em clubes e federações. Estas gestoras, em sua grande maioria, não concordam com as políticas de cotas que o Comitê Olímpico Internacional recomenda para as mulheres, por entenderem que seus cargos devem ser conquistados a partir do trabalho que desenvolvem em suas federações e não, simplesmente, por serem mulheres.

Outro fator limitador da maior inserção das mulheres (e não apenas elas) na gestão esportiva reside na organização do esporte descrita pela autora como um sistema de "castas" presente em vários clubes brasileiros. Neste sistema, são os laços familiares aqueles que, muitas vezes, contam para a progressão na carreira em detrimento da indicação de gestores e gestoras, ainda que competentes.

Enfim, apesar vários desafios enfrentados por essas mulheres, sua participação na gestão possibilita que sua ocupação se torne visível indicando, inclusive, a sua possibilidade de existência. Talvez seja esse o grande mérito do trabalho desenvolvido por Euza Gomes, não só para pensar o campo esportivo mas, ainda, outros espaços sociais nos quais as mulheres têm pouca inserção e cujo reconhecimento é inferior ao atribuído aos homens, mesmo quando desempenham a mesma função ou realizam o mesmo trabalho.

As gestoras entrevistadas por Euza enfatizam que se sentem aptas e competentes para se manterem à frente de suas entidades. Suas narrativas podem ser observadas como vozes que anunciam novos ares para o esporte brasileiro, pois, mesmo que não mencionem explicitamente, o que se apreende das suas falas é a imensa

Movimento, Porto Alegre, v. 15, n. 02, p. 235-242, abril/junho de 2009. 
desigualdade de gênero presente no campo da gestão esportiva no Brasil. E é por esse motivo que o livro Participação das Mulheres na Gestão do Esporte Brasileiro: desafios e perspectivas, revela-se como pioneiro, cuja leitura pode colaborar para entendermos as relações de poder que permeiam o esporte, mais especificamente, no âmbito da gestão.

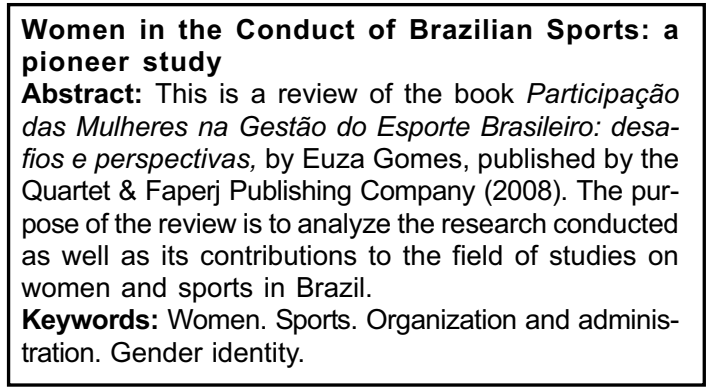

Las Mujeres en la Gestión del Deporte Brasileño:
un estudio pionero
Resumen: Se trata de la reseña del Libro Participação
das Mulheres na Gestão do Esporte Brasileiro: desa-
fios e perspectivas, escrito por Euza Gomes y publi-
cado por la editora Quartet y Faperj (2008). Tiene como
objetivo analizar la investigación realizada así como
sus contribuciones para el campo de los estudios
sobre mujeres y deportes en Brasil.
Palabras Clave: Mujeres. Deportes. Organización y
administración. Identidad de género

\section{REFERÊNCIAS:}

OLIVEIRA, G. A. de S. Representações sociais de mulheres técnicas sobre o comando de equipes esportivas de alto nível. 2002. 235f. Dissertação (Mestrado) - Programa de Pós-Graduação em Educação Física, Departamento de Educação Física, UGF. Rio de Janeiro, 2002

VENTURI, G.; RECAMÁN, M.; OLIVEIRA, S. de. A mulher brasileira nos espaços público e privado. São Paulo: Fundação Perseu Abramo, 2001.

Recebido em: 17.11.2008

Aprovado em: 31.03. 2009

Movimento, Porto Alegre, v. 15, n. 02, p. 235-242, abril/junho de 2009. 